\title{
Pilihan Jenis Pelayanan Bidan pada Masyarakat Urban, Sub-Urban
} dan Rural

\author{
Sefita Aryuti Nirmala ${ }^{1}$ dan Ariyati Mandiri ${ }^{2}$ \\ 1,2Program Studi D4 Kebidanan, Departemen Ilmu Kesehatan Masyarakat, Fakultas Kedokteran \\ Universitas Padjadjaran \\ sefita@unpad.ac.id ${ }^{1}$, ariyati.mandiri@unpad.ac.id²
}

\author{
Diajukan 1 Oktober 2020 Diperbaiki 17 November 2020 Diterima 30 November 2020 \\ ABSTRAK
}

Latar Belakang: Data WHO menunjukkan angka kematian ibu di dunia dari tahun 2000 hingga 2017 mengalami penurunan sebesar $38 \%$. Angka kematian ibu di dunia, $94 \%$ berada pada negara miskin dan berbagai faktor pendukung lainnya. Hal tersebut tidak jauh berbeda dengan kondisi di Indonesia. Keberadaan bidan di Indonesia sangat membantu akses pelayanan kesehatan. Layanan kebidanan dapat diakses mulai dari fasilitas pelayanan kesehatan primer hingga tingkat tersier dan menyebar di berbagai wilayah. Terdapat berbagai faktor yang mempengaruhi masyarakat dalam memilih jasa layanan bidan.

Tujuan: Penelitian ini bertujuan untuk mengetahui gambaran jenis pelayanan bidan yang dipilih oleh masyarakat di daerah urban, sub-urban dan rural.

Metode: Metode penelitian deskriptif dengan pendekatan cross sectional dan menggunakan data primer dengan responden berjumlah 300 orang. Lokasi penelitian daerah urban di Kecamatan Buahbatu, Kota Bandung, daerah sub-urban di Kecamatan Jatinangor, Kabupaten Sumedang dan Kecamatan Rancaekek, Kabupaten Bandung. Daerah rural di Kecamatan Pamulihan, Kabupaten Sumedang.

Hasil: Hasil penelitian didapatkan masyarakat sub-urban terbanyak menggunakan jasa bidan yaitu $97 \%$. Jenis layanan paling banyak pada pemeriksaan kehamilan $96 \%$ dan diikuti $79 \%$ pertolongan persalinan pada masyarakat sama yaitu daerah sub-urban.

Kesimpulan: Masyarakat sub-urban paling banyak menggunakan jasa layanan bidan dengan pilihan jenis layanan pemeriksaan kehamilan dan persalinan.

Kata Kunci: Pelayanan Bidan; Rural; Sub-Urban; Urban

\section{ABSTRACT}

Background: WHO data showed maternal mortality rate from 2000 until 2017 has decreased by 38\%. As many as $94 \%$ of the wolrd's maternal mortality rate is in poor countries and other supporting factors. This is not much different from condition in Indonesia. The existence of a midwife in Indonesia is very helpful in accessing health services. Midwife services can be accessed from primery health care facilities to tertiary health care facilities and spread in various regions. There are various factors that influence the community in choosing midwife services.

Objective: The purpose of this study was to determine the description of the types of midwife services chosen by the community in urban, sub-urban and rural areas.

Method: This research method is descriptive with cross sectional approach and used primary data and sample were 300 respondents. The location of the study were urban area in Buahbatu Subdistrict at Bandung City, suburban areas in Jatinangor Sub-district at Sumedang District and Rancaekek Sub-districts at Bandung District.

Results: The rural area in Pamulihan Sub-District at Sumedang District. The results showed that most suburban communities used the services of midwives were 97\%. The most types of services at $96 \%$ pregnancy checkups and $79 \%$ childbirth service to the same community are sub-urban areas.

Conclusion: Sub-urban communities use the most midwife services with a choice of pregnancy checkup and childbirth services.

Keywords: Midwife services; Rural; Sub-Urban; Urban 
PENDAHULUAN

Sudah sejak lama profesi bidan ada di berbagai belahan dunia. Bidan tergolong profesi yang berumur tua. Berbagai negara menyediakan layanan kebidanan sudah sejak jaman kuno. Pada jaman tersebut layanan ini diberikan oleh dukun beranak dengan menggunakan ketajaman intuisi serta peralatan yang sederhana. Seorang dukun mengutamakan pengalaman dalam menolong persalinan atau dalam memberikan layanan lainnya. Namun, seiring dengan perkembangan ilmu dan teknologi, layanan kebidanan dituntut dengan berbasis ilmu, memiliki standar pelayanan, serta profesional dalam memberikan pelayanan.

Di Indonesia, profesi bidan sangat dikenal dan termasuk profesi yang dianggap mulia di masyarakat. Keberadaan bidan sangat membantu dalam akses untuk mendapatkan pelayanan kesehatan. Keberadaan bidan di Indonesia tentunya sangat berkontribusi terhadap derajat kesehatan ibu dan anak.

Indikator keberhasilan suatu negara diantaranya menurunnya angka kematian ibu dan anak. Berdasarkan survei Badan Pusat Statistik tahun 2015, angka kematian ibu sebanyak 305 kasus dalam 100.000 kasus kelahiran hidup. Angka ini mengalami penurunan dibanding tahun 2010 yaitu, 346 kasus dalam 100.000 kasus kelahiran hidup. Data WHO menunjukkan angka kematian ibu di dunia dari tahun 2000 hingga 2017 mengalami penurunan sebesar $38 \%$. Angka kematian ibu di dunia sebanyak 94\%, berada pada negara miskin (Kementerian Kesehatan RI, 2018). Negara Indonesia sendiri, pada umumnya disebabkan karena ibu yang kurang mendapatkan fasilitas pelayanan kesehatan yang baik karena faktor kemiskinan, jarak yang jauh dengan fasilitas kesehatan, informasi layanan yang tidak memadai, adanya praktik keyakinan, dan budaya yang buruk. Hal serupa pada negara Kanada, pada tingkat sosial ekonomi yang rendah, akses pelayanan kebidanan terhambat karena kurang pemahaman masyarakat pada tingkat tersebut (Darling et al., 2019).

Tentunya, dengan adanya layanan bidan di masyarakat, diharapkan dapat membantu mengurangi faktor penyebab serta pendukung terjadinya kesakitan dan kematian ibu dan anak. Penempatan tugas bidan di daerah desa (rural), sub-urban ataupun di perkotaan (urban) dianggap dapat membantu masyarakat untuk memudahkan dalam mendapatkan akses layanan kesehatan. Fakta tentang jumlah tenaga bidan di Puskesmas, menurut data Profil Kesehatan Indonesia tahun 2017, bidan merupakan sumber daya manusia kesehatan di Puskesmas paling banyak yakni berjumlah 36,14\%, sedangkan kecukupan jumlah bidan di Puskesmas yaitu $81,9 \%$ Puskesmas memiliki jumlah bidan lebih dari standar yang ditetapkan, $4,23 \%$ sudah cukup bidan dan 13,9\% kekurangan bidan.

Di Provinsi Jawa Barat, kecukupan bidan yang berada di Puskesmas 88,47\% lebih dari standar, 7,84\% kurang dan 3,69\% cukup (Kementerian Kesehatan RI, 2018). Tenaga kesehatan bidan juga dapat memberikan pelayanan yang dapat menjangkau pada populasi masyarakat yang rentan. Namun, pada banyak negara dokumetasi terhadap pelayanan bidan pada masyarakat rentan adalah minim, sehingga tidak dapat disebarluarkan informasi layanan tersebut (Dawson et al., 2015).

Berdasarkan Undang-Undang Republik Indonesia Nomor 4 Tahun 2019 Tentang Kebidanan, bidan mendapatkan paling banyak dua SIPB yaitu satu di Tempat Praktik Mandiri dan satu di fasilitas kesehatan selain di tempat praktik mandiri atau dapat kedua-duanya, di tempat fasilitas kesehatan selain tempat praktik bidan. Pada peraturan baru yang berlaku, bidan juga dapat membuka praktik mandiri berdasarkan persyaratan 
Pilihan Jenis Pelayanan Bidan pada Masyarakat Urban...

tertentu. Hal tersebut dapat membantu bidan untuk menyelenggarakan praktik kebidanan tidak hanya di Puskesmas, Rumah Sakit atau Klinik. Bidan memiliki peluang untuk membuka praktik mandiri dengan wilayah baik urban, sub-urban dan rural sehingga membantu akses pelayanan kesehatan ibu dan anak.

Studi yang dilakukan oleh Tinah \& Fidianata (2018) menunjukkan bahwa pelayanan Bidan di desa menunjukkan tingkat kepuasan cukup adalah paling banyak dirasakan oleh masyarakat. Dalam penelitian tersebut juga didapatkan tingkat kepuasan masyarakat memiliki korelasi terhadap kunjungan pasien. Adapun dari hasil penelitian $\mathrm{Abu}$ et al. (2017), didapatkan bahwa karakteristik bidan yaitu umur berpengaruh terhadap mutu pelayanan, begitu pula dengan masa kerja. Lamanya masa kerja identik dengan banyaknya pengalaman yang didapatkan.

Hal lain yang menjadi tantangan bidan adalah pengaruh sosial budaya yang sangat kuat melekat pada kehidupan masyarakat. Bidan perlu memahami terkait sosial budaya masyarakat yang merupakan wilayah kerja. Hasil penelitian Thackrah et al. (2014), menunjukkan bahwa pengalaman belajar terhadap budaya tidak bisa didapatkan di kelas sehingga proses pembelajaran didapatkan langsung pada masyarakat yang memberikan keuntungan bagi mahasiswa. Hal tersebut berdampak pada kekuatan tradisi, sehingga membatasi pemberian pelayanan kesehatan serta memberikan kesadaran yang meningkat tentang kesulitan yang dialami oleh wanita (Thackrah et al., 2014).

Oleh karena itu, diharapkan bidan dalam memberikan pelayanan agar memahami budaya setempat. Salah satu tantangan bidan dan sudah menjadi akar yang kuat dalam tradisi adalah kepercayaan masyarakat yang tinggi pada dukun. Dukun sangat populer di masyarakat. Pekerjaan ini diturunkan dari orang tua ke anak dan cucu dengan pemberian layanan berdasarkan pengalaman. Studi Kurniati et al. (2019), melakukan studi faktor-faktor yang berhubungan dengan penggunaan jasa dukun pada ibu nifas dipengaruhi oleh tingkat pendidikan, wilayah tempat tinggal, biaya yang lebih murah dibandingkan dengan rumah sakit, pengalaman semua keluarga yang menggunakan jasa dukun, banyaknya pengguna jasa dukun pada lingkungan sekitar serta dukungan dari keluarga terdekat.

Lalu bagaimana dengan pemahaman masyarakat terhadap jasa layanan bidan? Apakah masyarakat memahami dengan benar tentang layanan yang diberikan oleh bidan? Tidak sedikit masyarakat beranggapan bahwa bidan selain menolong persalinan juga dapat membantu mengobati penyakit. Apakah masyarakat sudah memanfaatkan keberadaan profesi bidan sesuai dengan peran dan fungsinya? Berdasarkan penjelasan tersebut, peneliti tertarik untuk mengetahui jenis layanan yang dipilih oleh masyarakat pada tiga wilayah berbeda yaitu urban, sub-urban dan rural.

\section{METODOLOGI PENELITIAN}

Penelitian ini merupakan suatu survei deskriptif dengan pendekatan cross sectional. Lokasi penelitian dilakukan di tiga daerah berbeda yaitu urban di Kelurahan Sekejati, Kecamatan Buahbatu, Kota Bandung, sub-urban di Desa Bojong Soa, Kecamatan Rancaekek, dan Desa Hegarmanah Kecamatan Jatinangor, kemudian daerah rural yaitu Desa Sukawangi, Kecamatan Pamulihan, Kabupaten Sumedang. Sampel penelitian berjumlah 300 responden yang masingmasing lokasi penelitian sebanyak 100 responden (Dahlan, 2010).

Data yang dikumpulkan merupakan data primer yaitu berupa pengisian kuesioner dan hasil wawancara (Widoyoko, 2012). Prosedur mengambilan 
Pilihan Jenis Pelayanan Bidan pada Masyarakat Urban...

data dilakukan dengan cara kunjungan rumah pada warga terpilih. Setelah mendapatkan ijin dan warga menyetujui, maka dilakukan pengisian kuesioner dan wawancara (Danim, 2004). Analisis data yang digunakan yakni analisis univariat berupa hasil pengisian kuesioner dan sebagai tambahan menyimpulkan hasil wawancara (Dahlan, 2011).

\section{HASIL DAN PEMBAHASAN}

Hasil penelitian menunjukkan bahwa pengguna dan jenis pilihan layanan bidan yang didapatkan masyarakat urban, suburban dan rural dapat dilihat pada Tabel 1 dan Tabel 2.

Tabel 1. Pengguna Jasa Layanan Bidan

\begin{tabular}{llcccccc}
\hline \multirow{2}{*}{ No Daerah } & \multicolumn{3}{c}{ Ya } & \multicolumn{2}{c}{ Tidak } & \multicolumn{2}{c}{ Abstain } \\
& & f & \% & f & \% & f & \% \\
\hline 1 & Urban & 73 & 24,33 & 2 & 4,00 & 15 & 5,00 \\
2 & Sub-urban & 96 & 32,00 & & 1,33 & 0 & 0 \\
3 & Rural & 75 & 25,00 & 25 & 8,33 & 0 & 0 \\
& Jumlah & 244 & 81,33 & 1 & 13,67 & 15 & 5,00 \\
\hline
\end{tabular}

Data pada Tabel 1 menunjukkan bahwa masyarakat baik di daerah urban, sub-urban, dan rural yang menggunakan jasa layanan bidan sebesar $81,33 \%$. Daerah sub-urban sebagai pengguna layanan bidan terbanyak yaitu 32,00\%, namun juga terdapat masyarakat yang tidak menjawab (abstain) sebanyak 5\%.

Wilayah sub-urban adalah suatu daerah perbatasan antara kota dan desa. Salah satu ciri dari wilayah sub-urban yaitu pesatnya perkembangan transportasi umum, fasilitas publik dan kecenderungan masyarakatnya yang menyerupai dengan masyarakat kota. Namun demikian, unsur kemandirian, tingkat pendidikan, dan pekerjaan lebih baik pada masyarakat kota. Wilayah suburban ada akibat dari padatnya daerah perkotaan, sehingga terjadi perluasan atau pergeseran penduduk yang merambah ke luar kota. Fenomena sub-urban semakin banyak terjadi, perkembangan lebih lanjut sub-urban dapat menjadi post sub-urbania dengan ditunjukkan adanya lokasi spesifik untuk pusat permukiman, perbelanjaan, dan komplek industri. Keterpisahan antara pusat tersebut ditunjukkan dengan adanya spesialisasi fungsi kegiatan dan berlokasi dalam waktu tempuh 15 - 30 menit perjalanan antara satu dengan yang lain (Sadewo et al., 2018)

Berdasarkan Tabel 1, masyarakat suburban adalah kelompok terbanyak yang menggunakan jasa layanan kebidanan yaitu $32,00 \%$. Bidan menjadi pilihan nomor satu dalam layanan kesehatan ibu dan anak. Hal tersebut menjadi fakta bahwa bidan pada daerah sub-urban merupakan tenaga kesehatan yang paling mudah untuk dijangkau dan sangat dikenal oleh masyarakat sub-urban. Pilihan tersebut juga menggambarkan bahwa jumlah bidan lebih banyak dibandingkan dokter.

Hasil wawancara sederhana, pada masyarakat sub-urban lebih memilih bidan karena bidan dapat dekat dan diterima oleh masyarakat. Selain itu, pemahaman masyarakat sub-urban pada penelitian ini juga mengetahui bahwa dukun atau di Jawa Barat lebih dikenal dengan sebutan "mak paraji" tidak diperbolehkan lagi memberikan pertolongan persalinan, sehingga keberadaan bidan jadi lebih dibutuhkan. Namun, masyarakat suburban mengharapkan pelayanan yang diberikan oleh bidan dapat seperti "mak paraji" yang lebih menguatkan sisi humanistis, empati serta ketulusan dalam memberi pelayanan.

Studi kualitatif yang dilakukan oleh Trudde Thommensen et al. (2020) menunjukkan bahwa pengguna layanan merasakan perlunya penguatan pada softskill bidan seperti sopan santun dan komunikasi yang saling menghormati dalam memberikan pelayanan. Solusi yang dapat dilakukan adalah dengan melakukan pelatihan bagi bidan. Selain pelatihan, solusi yang dapat dilakukan adalah dengan menerapkan asuhan kebidanan secara komprehensif dengan 
Pilihan Jenis Pelayanan Bidan pada Masyarakat Urban...

berorientasi pada ibu. Hasil penelitian yang dilakukan oleh Zoe Bradfiled et al. (2019), didapatkan melalui model pendekatan dalam memberikan konsep asuhan kebidanan yaitu "turut merasakan menjadi ibu", terbangunnya rasa saling mempercayai, dan fokus pelayanan pada ibu dan dapat memberikan pengalaman bagi bidan untuk menerapkan filosofi kebidanan dan memunculkan nilai humanistis, empati, dan sosial (Bradfield et al., 2019).

Harapan lainnya dari masyarakat suburban yakni bidan dapat memberikan pelayanan yang berkelanjutan, sehingga masyarakat merasa nyaman dan mendapatkan perhatian. Berdasarkan penelitian yang dilakukan oleh Mclness et al., pelayanan atau asuhan berkelanjutan dapat berjalan dengan baik dengan adanya kepercayaan antara ibu dan bidan, selain itu dukungan dari pimpinan tim sangat membantu dalam mendorong asuhan keberlanjutan yang sedang berjalan (McInnes et al., 2020). Oleh karena itu, dengan membangun tim dalam layanan kebidanan komunitas sangat memungkinkan harapan masyarakat tercapai dan mutu kualitas layanan akan lebih terpantau.

Pada penelitian ini, di wilayah rural atau desa ditemukan 25\% masyarakat menggunakan jasa layanan bidan dan ini merupakan kelompok kedua terbanyak setelah masyarakat sub-urban. Masyarakat rural merupakan masyarakat yang jauh dengan wilayah perkotaan, sehingga kehidupannya cenderung menyatu dengan alam. Budaya yang terbentuk dalam masyarakat desa berdasarkan ikatan kekeluargaan yang kuat. Perkembangan sosialnya lambat dengan sosial kontrol kuat ditentukan oleh nilai moral dan masih berlaku hukum adat.

Saat ini pemerintah sangat giat membangun jalan termasuk pada daerah desa yang bertujuan agar mempermudah laju pertumbuhan ekonomi. Tentunya adaptasi terjadi pada tatanan sosial masyarakat desa, namun masih memiliki ciri khas yang berbeda pada masyarakat kota maupun sub-urban. Budaya dan karakteristik sosial dari masing-masing wilayah membawa makna terhadap pemanfaatan fasilitas kesehatan, termasuk pemilihan tenaga kesehatan. Dampak lainnya adalah termasuk pada pemilihan jenis pelayanan. Pada Tabel 2, Tabel 3, dan Tabel 4 dapat dilihat jenis layanan kebidanan yang digunakan pada 3 kelompok masyarakat yang berbeda.

Tabel 2. Jenis Layanan Bidan yang Digunakan pada Daerah Urban

\begin{tabular}{llccc}
\hline No & $\begin{array}{c}\text { Jenis } \\
\text { Layanan }\end{array}$ & $\begin{array}{c}\text { Bidan } \\
\mathbf{f ( \% )}\end{array}$ & $\begin{array}{c}\text { Lainya } \\
\mathbf{f}(\%)\end{array}$ & Jumlah \\
\hline 1 & $\begin{array}{l}\text { Pemeriksaan } \\
\text { Kehamilan }\end{array}$ & $45(45 \%)$ & $55(55 \%)$ & $100 \%$ \\
2 & Persalinan & $55(55 \%)$ & $45(45 \%)$ & $100 \%$ \\
3 & Nifas & $25(25 \%)$ & $75(75 \%)$ & $100 \%$ \\
4 & Kontrasepsi & $33(33 \%)$ & $67(67 \%)$ & $100 \%$ \\
5 & $\begin{array}{l}\text { Konseling } \\
\text { kespro }\end{array}$ & $33(33 \%)$ & $67(67 \%)$ & $100 \%$ \\
& $\begin{array}{l}\text { Pemeriksaan } \\
\text { Bayi Balita }\end{array}$ & $32(32 \%)$ & $68(68 \%)$ & $100 \%$ \\
7 & $\begin{array}{l}\text { Imunisasi } \\
\text { Pemeriksaan }\end{array}$ & $21(21 \%)$ & $79(79 \%)$ & $100 \%$ \\
\hline
\end{tabular}

Hasil dari penelitian ini, pada daerah urban dapat dilihat pada Tabel 2 bahwa jenis pelayanan yang paling banyak dipilih oleh masyarakat urban yaitu pertolongan persalinan sebesar 55\%. Pada daerah perkotaan, masyarakat lebih banyak untuk memilih tenaga kesehatan untuk membantu persalinan. Hal tersebut sangat wajar, karena daerah perkotaan fasilitas kesehatan termasuk tenaga kesehatan banyak tersedia. Namun, masyarakat kota memilih bidan dengan alasan jenis persalinan normal lebih banyak ditangani bidan dibandingkan dengan persalinan tidak normal. Dalam Undang-Undang Republik Indonesia Nomor 4 Tahun 2019 Tentang Kebidanan, tertuang bahwa bidan memiliki kewenangan dalam menolong persalinan normal.

Alasan lainnya, pada masyarakat kota memiliki tingkat pendidikan yang 
Pilihan Jenis Pelayanan Bidan pada Masyarakat Urban...

tinggi. Pemahaman masyarakat terkait kesehatan tentunya jauh lebih baik. Persalinan bukan saja menjadi satu kejadian yang dapat diatasi dalam satu waktu, tetapi persalinan merupakan satu kesatuan akumulasi dari mulai persiapan kehamilan, menjalankan kehamilan dengan sehat, karena itu dibutuhkan persiapan dari ibu beserta keluarga agar dapat bersalin dengan sehat. Melalui tingkat pendidikan yang lebih tinggi, pemahaman sehat sejak dini sudah menjadi suatu pemahaman yang baik bagi masyarakat kota, sehingga seorang ibu hamil lebih banyak untuk menjaga diri untuk terus menjadi sehat.

Salah satu peluang yang dapat diambil dengan tingkat pendidikan yang lebih tinggi di wilayah perkotaan adalah keterlibatan keluarga sebagai pendamping persalinan. Penelitian Kurniati et al. (2017) menunjukkan bahwa program suami siaga dapat meningkatkan derajat kesehatan ibu. Program suami siaga juga mendorong kehadiran suami untuk mendampingi pemeriksaan kehamilan. Proses pemberdayaan perempuan semakin mudah dan berhasil dengan adanya dukungan dari suami.

Tren yang berkembang di masyarakat kota saat ini lebih menekankan pada konsep alamiah. Jika segala sesuatunya dijalankan dengan alamiah, maka risiko akan lebih sedikit. Bidan memiliki peran sebagai pendamping persalinan. Makna ini adalah bukan hanya sebagai membantu kelahiran bayi, tetapi bidan memiliki peran dan tanggung jawab dalam pemantauan kemajuan persalinan sekaligus memberikan dukungan pada ibu sehingga membuat ibu dalam keadaan aman dan nyaman untuk dapat melalui persalinan secara normal dan sehat. Kompetensi lainnya yang dimiliki bidan adalah dapat melakukan pendekatan yang baik terhadap ibu dan keluarga, oleh karena itu rasa percaya muncul dan ibu dan dapat berkoordinasi dengan baik selama proses persalinan.
Pada Tabel 2, masyarakat urban memilih bidan untuk pemeriksaan ketika sakit sebanyak 21\%. Apabila dilihat dari kewenangan bidan, tentunya tidak diperbolehkan untuk mengobati penyakit. Hal tersebut menunjukkan bahwa tidak semua masyarakat kota paham terhadap peran dan fungsi kerberadaan bidan. Ketersediaan fasilitas kesehatan yang beragam dan mudah diakses, seharusnya masyarakat kota dapat mengambil keputusan yang tepat memilih tenaga kesehatan dan fasilitas pelayanan kesehatan untuk mengobati ketika sakit.

Tabel 3. Jenis Layanan Bidan yang Digunakan pada Daerah Sub-Urban

\begin{tabular}{|c|c|c|c|c|}
\hline No & $\begin{array}{l}\text { Jenis } \\
\text { Layanan }\end{array}$ & $\begin{array}{l}\text { Bidan } \\
\text { f ( } \%)\end{array}$ & $\begin{array}{c}\text { Lainya } \\
\text { f (\%) }\end{array}$ & Jumlah \\
\hline 1 & $\begin{array}{l}\text { Pemeriksaan } \\
\text { Kehamilan }\end{array}$ & 96 (96\%) & $4(4 \%)$ & $100 \%$ \\
\hline 2 & Persalinan & 79 (79\%) & $21(21 \%)$ & $100 \%$ \\
\hline 3 & Nifas & $59(59 \%)$ & $41(41 \%)$ & $100 \%$ \\
\hline 4 & Kontrasepsi & $64(64 \%)$ & $36(36 \%)$ & $100 \%$ \\
\hline 5 & $\begin{array}{l}\text { Konseling } \\
\text { kespro }\end{array}$ & $36(36 \%)$ & $64(64 \%)$ & $100 \%$ \\
\hline 6 & $\begin{array}{l}\text { Pemeriksaan } \\
\text { Bayi Balita }\end{array}$ & $63(63 \%)$ & 37 (37\%) & $100 \%$ \\
\hline 7 & Imunisasi & $72(72 \%)$ & $28(28 \%)$ & $100 \%$ \\
\hline 8 & $\begin{array}{l}\text { Pemeriksaan } \\
\text { sakit }\end{array}$ & 49 (49\%) & $51(51 \%)$ & $100 \%$ \\
\hline
\end{tabular}

Tabel 3 merupakan jenis layanan bidan yang dipilih oleh masyarakat suburban dengan pemilihan paling banyak pada pemeriksaan kehamilan $96 \%$. Meskipun sub-urban merupakan daerah yang dekat dengan kota, tetapi fasilitas dan tenaga kesehatan tidak sebanyak di kota, sehingga masyarakat sub-urban memiliki keterbatasan dalam memilih tenaga kesehatan. Daerah sub-urban pada umumnya memiliki bidan desa untuk mempermudah akses layanan kesehatan.

Hasil wawancara sederhana, pada kelompok masyarakat sub-urban telah mengetahui bahwa dukun tidak diperbolehkan, karena itulah hanya $4 \%$ masyarakat yang memeriksakan kehamilan pada tenaga kesehatan lainnya. Menjaga mutu kualitas pelayanan juga faktor yang berpengaruh terhadap 
pemilihan masyarakat terhadap layanan bidan. Hasil penelitian yang dilakukan oleh Abu et al. (2017) menunjukkan bahwa pengetahuan, umur dan masa kerja memiliki hubungan yang signifikan terhadap kualitas layanan kehamilan. Penguatan konsep kemitraan yang dilakukan bidan, sudah banyak yang dapat mengalihfungsikan dukun menjadi kader.

Apabila dilihat Tabel 3, pada jenis layanan persalinan $79 \%$ masyarakat suburban memilih bidan sebagai penolong persalinan. Angka pemeriksaan kehamilan jika dibandingkan dengan persalinan mengalami penurunan. Banyak faktor yang menyebabkan masalah tersebut, diantaranya adalah tingkat pendidikan masyarakat, budaya dan tingkat ekonomi. Faktor-faktor tersebut dapat sebagai penyebab kurang pahamnya masyarakat menjaga kesehatannya atau kehamilannya, sehingga kejadian komplikasi kehamilan atau persalinan mudah terjadi. Hal lain yang masih dapat terjadi adalah dukun masih berperan akitf. Daerah sub-urban tatanan sosialnya juga masih cukup kental dengan budaya. Kepercayaan terhadap dukun masih bisa ditemui di daerah suburban sehingga masyarakat juga dapat meminta bantuan pada dukun.

Pada Tabel 3 jenis layanan kesehatan reproduksi menjadi paling sedikit di masyarakat sub-urban. Berdasarkan wawancara, masyarakat sub-urban beranggapan apabila membicarakan masalah kesehatan reproduksi menjadi tabu dan kebanyakan perempuan malu untuk mengungkapkan masalahnya, karena itulah hanya sedikit masyarakat yang datang ke bidan untuk membantu masalah kesehatan reproduksinya.

Tabel 4. Jenis Layanan Bidan yang Digunakan pada Daerah Rural

\begin{tabular}{llccc}
\hline No & $\begin{array}{c}\text { Jenis } \\
\text { Layanan }\end{array}$ & $\begin{array}{c}\text { Bidan } \\
\mathbf{f ( \% )}\end{array}$ & $\begin{array}{c}\text { Lainya } \\
\mathbf{f ~ ( \% )}\end{array}$ & Jumlah \\
\hline 1 & $\begin{array}{l}\text { Pemeriksaan } \\
\text { Kehamilan }\end{array}$ & $58(58 \%)$ & $42(42 \%)$ & $100 \%$ \\
2 & Persalinan & $67(67 \%)$ & $33(33 \%)$ & $100 \%$
\end{tabular}

\begin{tabular}{lllll}
\hline 3 & Nifas & $39(39 \%)$ & $61(61 \%)$ & $100 \%$ \\
4 & Kontrasepsi & $47(47 \%)$ & $53(53 \%)$ & $100 \%$ \\
& $\begin{array}{l}\text { Konseling } \\
\text { kespro }\end{array}$ & $26(26 \%)$ & $74(74 \%)$ & $100 \%$ \\
& $\begin{array}{l}\text { Pemeriksaan } \\
\text { Bayi Balita }\end{array}$ & $35(35 \%)$ & $65(65 \%)$ & $100 \%$ \\
7 & $\begin{array}{l}\text { Imunisasi } \\
8\end{array}$ & $42(42 \%)$ & $58(58 \%)$ & $100 \%$ \\
$\begin{array}{l}\text { Pemeriksaan } \\
\text { sakit }\end{array}$ & $31(31 \%)$ & $69(69 \%)$ & $100 \%$ \\
\hline
\end{tabular}

Tabel 4 merupakan data yang ditemukan pada masyarakat rural atau desa. Jenis layanan bidan yang paling banyak digunakan oleh masyarakat rural atau desa adalah pelayanan persalinan sebasar $67 \%$. Studi yang dilakukan oleh Laila \& Masitoh (2019), ditemukan bahwa persalinan oleh tenaga kesehatan dipengaruhi oleh pekerjaan, tingkat pengetahuan, jarak tempat tinggal dan dukungan keluarga. Pengaruh lainnya adalah kentalnya sosial budaya di Indonesia, sehingga alasan persamaan gender sebagai perempuan, akan menghilangkan rasa sungkan dan malu bagi perempuan untuk melakukan pemeriksan dan berkonsultasi. Penguat lainnya adalah bidan sebagai wanita dapat memahami kebutuhan pasiennya.

Hal ini sejalan dengan penelitian yang dilakukan oleh Bradfield et al. (2019), bahwa menempatkan diri sebagai seorang wanita, dapat membina hubungan baik antara pasien dan keluarga sehingga muncul adanya kepercayaan. Menempatkan diri sebagai wanita atau merasakan sebagai wanita menurut hasil penelitian Bradfield et al. (2019) akan memperkuat penghayatan filosofi bidan, sehingga bidan dalam melakukan pemberdayaan serta memberikan asuhan dapat berkesinambungan.

Hasil wawancara pada masyarakat rural, profesi bidan sangat dekat dengan masyarakat. Pelayanan imunisasi bisa diberikan pada bidan. Pada masyarakat rural masih terdapat masyarakat yang belum mengetahui bahwa layanan kesehatan reproduksi lainnya bisa diberikan oleh bidan. Bidan menurut 
masyarakat rural juga tenaga kesehatan yang dapat membantu apabila ada anggota keluarga yang sakit untuk diperiksa sekaligus mendapatkan obat. Bidan juga dianggap dapat sebagai penolong masyarakat. Keberadaan bidan di daerah rural sangat membantu masyarakat dalam akses pelayanan kesehatan.

Penelitian yang dilakukan oleh McInnes et al. (2020) di Skotlandia dan Inggris, didapatkan bahwa adanya kepercayaan dari pasien menjadi faktor keberlangsungan bidan dalam menjalankan profesinya. Dukungan lainnya adalah bidan harus memiliki softskill kepemimpinan yang baik, mampu dalam melakukan manajemen pelayanan, serta mampu dalam melakukan pemberdayaan pada wanita.

Suatu studi yang dilakukan oleh Darra et al. (2016), bidan dalam memberikan pelayanan mempertahankan beberapa model asuhan. Melalui penerapan supervisi bidan dapat dijadikan role model bagi bidan lainnya. Jaringan yang dibentuk sangat membantu dalam menyelesaikan masalah kesehatan ibu dan anak, karena proses menghargai kerjasama dan mengandalkan, mampu bekerja dalam tim menjadi motor penggerak memberikan asuhan kebidanan. Model supervisi ini tidak hanya diterapkan bagi bidan yang bekerja, dapat pula melibatkan mahasiswa bidan sebagai generasi penerus. Role model akan memberikan pengalaman berharga bagi mahasiswa bidan. Model seperti ini dapat menjadi suatu solusi sebagai penguatan asuhan kebidanan untuk membantu penurunan angka kematian ibu dan anak.

\section{PENUTUP}

Kesimpulan pada penelitian ini adalah ditemukan bahwa masyarakat suburban merupakan masyarakat terbanyak (96\%) yang menggunakan jasa layanan bidan. Pada masyarakat urban pilihan terbanyak jenis pelayanan bidan adalah persalinan $(55 \%)$, masyarakat sub-urban pada jenis terbanyak layanan bidan berupa pemeriksaan kehamilan (96\%) dan pada masyarakat rural paling banyak adalah jenis layanan bidan berupa persalinan $(67 \%)$.

Keberagaman

karakteristik masyarakat serta pengasuh sosial budaya dapat mempengaruhi masyarakat dalam memilih layanan bidan. Pelayanan kebidanan yang berkualitas dan profesional diinginkan oleh masyakarat. Melalui penerapan model asuhan kebidanan yang berkesinambungan dan terpantau, dapat menjawab harapan masyarakat serta membantu dalam peningkatan kesehatan ibu dan anak.

\section{UCAPAN TERIMA KASIH}

Ucapan terima kasih tim peneliti sampaikan kepada seluruh masyarakat yang telah bersedia membantu penelitian ini yaitu warga di Kelurahan Sekejati, Kecamatan Buahbatu, Kota Bandung, Desa Bojong Soa, Kecamatan Rancaekek, Desa Hegarmanah, Kecamatan Jatinangor, serta Desa Sukawangi Kecamatan Pamulihan Kabupaten Sumedang.

Tim peneliti juga menyampaikan ucapan terima kasih atas koordinasi tim dosen pengampu mata kuliah Introduction Midwifery Profession (IMP). Ucapan terima kasih kami sampaikan pada Dekan Fakultas Kedokteran Universitas Padjadjaran beserta jajarannya yang telah memberikan fasiltas pada proses pembelajaran dan pengambilan data. Selain itu, tim peneliti juga berterima kasih atas kerjasama mahasiswa angkatan 2019 Prodi D4 Kebidanan FK Unpad sebagai enumerator dalam proses pengambilan data. Semoga dalam perjalanan sebagai enumerator banyak mendapatkan pengalaman terutama pengalaman berinteraksi dan berkomunikasi secara langsung dengan masyarakat sehingga mengetahui pandangan masyarakat terhadap profesi bidan dan dapat menjadi penguat 
motivasi dalam menempuh pendidikan.

\section{DAFTAR PUSTAKA}

Abu, A. D. K. H., Kusumawati, Y., \& Werdani, K. E. (2017). Hubungan Karakteristik Bidan dengan Mutu Pelayanan Antenatal Care berdasarkan Standar Operasional. Jurnal Kesehatan Masyarakat Andalas, 10(1), 94. https://doi.org/ 10.24893/jkma.v10i1.169

Bradfield, Z., Hauck, Y., Kelly, M., \& Duggan, R. (2019). "It's what midwifery is all about": Western Australian midwives' experiences of being 'with woman' during labour and birth in the known midwife model. BMC Pregnancy and Childbirth, 19(1), 29. https:// doi.org/10.1186/s12884-018-2144-z

Dahlan, M. S. (2010). Besar Sampel dan Cara Pengambilan Sampel (A. Susila (ed.); 3rd ed.). Salemba Medika.

Dahlan, M. S. (2011). Statistik untuk Kedokteran dan Kesehatan (5th ed.). Salemba Medika.

Danim, S. (2004). Metode Penelitian untuk Ilmu-Ilmu Perilaku (1st ed.). Bumi Aksara.

Darling, E. K., Grenier, L., Nussey, L., Murray-Davis, B., Hutton, E. K., \& Vanstone, M. (2019). Access to midwifery care for people of low socio-economic status: a qualitative descriptive study. BMC Pregnancy and Childbirth, 19(1), 416. https://doi.org/10.1186/s12884-0192577-z

Darra, S., Sanges, P., \& Wolfe, M. (2016). Minding the gap in midwifery supervision: findings from the 2016 Welsh LSA audit. Evidence Based Midwifery, 14(4), 119124. https://cronfa.swan.ac.uk/ Record/cronfa32322

Dawson, A. J., Nkowane, A. M., \& Whelan, A. (2015). Approaches to improving the contribution of the nursing and midwifery workforce to increasing universal access to primary health care for vulnerable populations: a systematic review. Human Resources for Health, 13(1), 97. https://doi.org/10.1186/s12960015-0096-1

Kementerian Kesehatan RI. (2018). Profil Kesehatan Indonesia Tahun 2017. Kementerian Kesehatan RI.

Kurniati, A., Chen, C.-M., Efendi, F., Elizabeth Ku, L.-J., \& Berliana, S. M. (2017). Suami SIAGA: male engagement in maternal health in Indonesia. Health Policy and Planning, 32(8), 1203-1211. https:// doi.org/10.1093/heapol/czx073

Kurniati, Nadyah, \& Darmawansyih. (2019). Gambaran Faktor-Faktor Yang Mempengaruhi Ibu Nifas Menggunakan Jasa Dukun di Wilayah Kerja Puskesmas Bontomarannu Kecamatan Galesong Selatan Kabupaten Takalar 2017. Journal Midwifery, 1(1), 58-67.

Laila, E. F., \& Masitoh, S. (2019). Determinan Pemilihan Penolong Persalinan Di Wilayah Kerja Puskesmas Cicantayan Kabupaten Sukabumi. Midwife Journal, 5(02), 36-50. http://jurnal.ibijabar.org/ wp-content/uploads/2019/09/ determinan-pemilihan-penolongpersalinan-di-wilayah-kerjapuskesmas-cicantayan-kabupatensukabumi.pdf

McInnes, R. J., Aitken-Arbuckle, A., Lake, S., Hollins Martin, C., \& MacArthur, J. (2020). Implementing continuity of midwife carer - just a friendly face? A realist evaluation. BMC Health Services Research, 20(1), 304. https://doi.org/10.1186/s12913-02005159-9

Sadewo, E., Syabri, I., \& Pradono, P. (2018). Post-suburbia dan Tantangan Pembangunan di Kawasan Pinggiran Metropolitan: 
Suatu Tinjauan Literatur. Majalah Geografi Indonesia, 32(2), 130. https:// doi.org/10.22146/mgi.32097

Thackrah, R. D., Thompson, S. C., \& Durey, A. (2014). "Listening to the silence quietly": investigating the value of cultural immersion and remote experiential learning in preparing midwifery students for clinical practice. BMC Research Notes, 7(1), 685. https://doi.org/ 10.1186/1756-0500-7-685

Thommesen, T., Kismul, H., Kaplan, I., Safi, K., \& Van den Bergh, G. (2020). "The midwife helped me ... otherwise I could have died": women's experience of professional midwifery services in rural Afghanistan - a qualitative study in the provinces Kunar and
Laghman. BMC Pregnancy and Childbirth, 20(1), 140. https:// doi.org/10.1186/s12884-020-2818-1

Tinah, A. H., \& Fidianata, A. R. (2018). Kepuasan Pasien Pada Pelayanan Bidan Di Poskeskes. Jurnal Kebidanan, 10(01), 28-37. http:// ejurnal.stikeseub.ac.id/index.php/ jkeb/article/view/296

Undang-Undang Republik Indonesia Nomor 4 Tahun 2019 Tentang Kebidanan, Pub. L. No. No.4 Tahun 2009 (2019). https:// jdih.bssn.go.id/wp-content/ uploads/2019/10/UU-Nomor-4Tahun-2019.pdf

Widoyoko, E. P. (2012). Tekini Penyusunan Instrumen Penelitian (Pertama). Pustaka Pelajar. 